\title{
Comparative study of head structures of larvae of Sphindidae and Protocucujidae (Coleoptera: Cucujoidea)
}

\author{
Rolf Georg BEUTEL ${ }^{1}$ and STANISLAW AdAm ŚLIPIŃSKI ${ }^{2}$ \\ ${ }^{1}$ Institut für Spezielle Zoologie und Evolutionsbiologie, FSU Jena, 07743 Jena, Germany; e-mail: b5bero@rz.uni-jena.de \\ ${ }^{2}$ Muzeum i Instytut Zoologii PAN, ul. Wilcza 64, 00-679 Warszawa, Poland, e-mail: adamsli@robal.miiz.waw.pl
}

Key words. Cucujoidea, Sphindidae, Protocucujidae, larvae, morphology, phylogeny

\begin{abstract}
Selected representatives of Cucujoidea, Cleroidea, Tenebrionoidea, Chrysomelidae, and Lymexylidae were examined. External and internal head structures of larvae of Sphindus americanus and Ericmodes spp. are described in detail. The data were analyzed cladistically. A sister group relationship between Sphindidae and Protocucujidae is suggested by the vertical position of the labrum. The monophyly of Cucujiformia is supported by the reduced dorsal and anterior tentorial arms, fusion of galea and lacinia, and the presence of tube-like salivary glands. Absence of M. tentoriopraementalis inferior and presence of a short prepharyngeal tube are potential synapomorphies of Cleroidea, Cucujoidea and Tenebrionoidea. The monophyly of Cleroidea and Cucujoidea is suggested by the unusual attachment of the M. tentoriostipitalis to the ventral side of the posterior hypopharynx. Cucujoidea are paraphyletic. The families Endomychidae, Coccinellidae and Nitidulidae are more closely related to the monophyletic Cleroidea, than to other cucujoid groups. Separation of the posterior tentorial arms from the tentorial bridge and presence of a maxillolabial complex are synapomorphic features of Cleroidea and these cucujoid families. For a reliable reconstruction of cucujoid interrelationships, further characters and taxa need to be studied.
\end{abstract}

\section{INTRODUCTION}

Sphindidae and Protocucujidae are two small families of Cucujoidea with 61 (McHugh \& Lewis, 2000) and seven species, respectively. All sphindids appear to be slime mould feeders as there are no records of larvae in habitats other than spore masses or plasmodia of Myxomycetes (McHugh, 1993). Adults and larvae of Protocucujidae have been collected from vegetation, but the biology of this group is still unknown (Ślipiński, 1998). Both families are considered as primitive by Lawrence (1991). A sister group relationship between them was proposed by Crowson (1954, 1955), and a cladistic analysis based on 19 adult and eight larval characters of representatives of five families is consistent with this hypothesis (Ślipiński, 1998). Illustrations and descriptions of larvae of Sphindidae are given by Böving \& Craighead (1931), Burakowski \& Ślipiński (1987), Lawrence (1991), Chiao \& McHugh (in press) and others, and Ślipiński (1998) gives a detailed description of larvae of Ericmodes. However, the internal features of immature stages of these groups and of other cucujoid families are virtually unknown. Therefore, the main purpose of this study is to provide anatomical data and more detailed information on external structures of larvae of Sphindidae, Protocucujidae and other groups of Cucujiformia. Characters that are likely to be useful for the clarification of the systematic position of both families are listed, presented as a data matrix, and discussed. A cladistic analysis of character states was carried out, mainly in order to obtain a more reliable assessment of character state polarity. However, it is evident that a much broader spectrum of taxa and characters is needed for a reconstruction of the phylogeny of the cucujoid, tenebrionoid and cleroid families.

\section{MATERIAL AND TECHNIQUES}

List of taxa examined:

Staphylinoidea: Hydraenidae, Ochthebius sp.

Derodontoidea: Derodontidae, Derodontus esotericus Lawrence 1979

Lymexyloidea: Lymexylidae, Elateroides dermestoides (Linnaeus 1761)

Cucujoidea: Cavognathidae, Zeonidicola sp.; Coccinellidae, Coccinella sp.; Endomychidae, Mycetina cruciata (Schaller 1783); Nitidulidae, Glischrochilus sp.; Protocucujidae, Ericmodes spp. (Chile); Silvanidae, Oryzaephilus sp., Silvanus sp.; Sphindidae, Sphindus americanus LeConte 1866

Cleroidea: Cleridae, Lemidia sp.; Melyridae, Collops sp.; Phycosecidae, Phycosecis sp.; Trogossitidae, Calytis sp., Temnoscheila sp.

Tenebrionoidea: Colydiidae, Bitoma crenata (Fabricius 1775); Pyrochroidae, Pyrochroa sp.

Chrysomeloidea: Chrysomelidae, Altica sp.

Specimens of Sphindus americanus, Ericmodes spp., Calytis sp., Temnoscheila sp., Lemidia sp., Collops sp., Zeonidicola $\mathrm{sp}$. and Mycetina cruciata were preserved in 70\% ethanol, those of Nosodendron fasciculare in Dubosq brasil and those of Elateroides dermestoides, Bitoma crenata, Pyrochroa sp. and Altica sp. in FAE (formalin-ethanol-acetic acid). Larvae of all species, with the exception of Temnoscheila sp., were embedded in Historesin, sectioned at 3-5 $\mu \mathrm{m}$, and stained with methylene-blue and acid fuchsin. Drawings were made using an ocular grid or a camera lucida (cross sections). For SEMs specimens were cleaned with ultrasonic sound, dried (critical point) and coated with gold. The brain of Sphindus americanus was reconstructed 

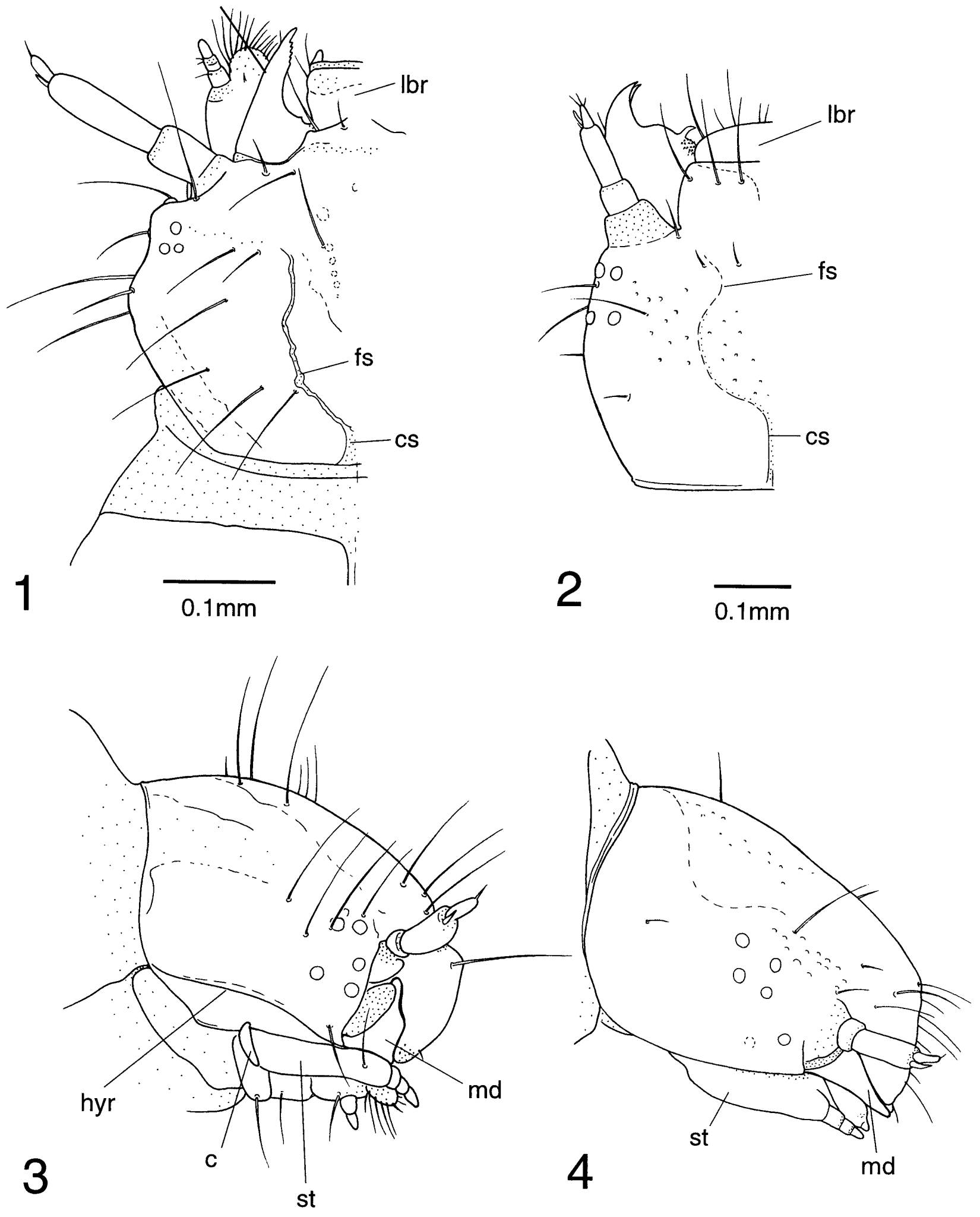

Figs 1-4: 1 - Larval heads of Sphindus americanus, dorsal view, head lifted anteriorly, normal orientation see Fig. 14; 2 - Ericmodes sp., dorsal view; 3 - Sphindus americanus, lateral view, head lifted anteriorly; 4 - and Ericmodes sp., lateral view. Abbreviations: c - cardo, cs - coronal suture, fs - frontal suture, hyr - hypostomal rod, lbr - labrum, md - mandible, st - stipes. 
three-dimensionally on a computer using ALIAS Wavefront software.

V. Kéler's (1963) muscular nomenclature is used in the text and the corresponding numbers are used in the illustrations.

\section{MORPHOLOGICAL RESULTS}

\section{Sphindus americanus}

General appearence of head capsule, external features

(Figs 1, 3, 14, 15)

Most parts dark brown in mature larvae, posterolateral and ventrolateral parts less strongly pigmented. Head almost hypognathous, only slightly flattened, distinctly rounded laterally. Dorsal and lateral parts with unusually long setae, distribution as in Figs 1, 3, 14, and 15. Six distinct stemmata present bilaterally, posterior to antennal articulating area. Three dorsolateral stemmata lie closely together. Labrum moveable, separated from clypeus by a membranous fold (Fig. 1). Antennae inserted anterolaterally. Clypeus separated from frons by a narrow, fairly indistinct membranous area. Anterior tentorial grooves not recognizable. Frons elongated. Frontal suture obliterated anteriorly, posterior part represented by an irregular membranous fissure. Coronal suture short, broad, membranous. Ventrolateral part of head capsule with distinct, very slightly diverging hypostomal rods. Maxillary grooves well developed. Gula absent (Fig. 14), paired membranous bulges posteriorly adjacent to submentum. Posterior tentorial arms arise immediately anterior to foramen occipitale.

\section{Internal skeletal structures (Figs 5-7)}

Posterior arms strongly developed, proximal part nearly horizontal, connected by strong tentorial bridge. Dorsal arms strongly flattened but still moderately developed, attached to dorsal wall of head capsule by a strong bundle of fibrillar structures. Anterior arms vestigial or absent, not identified in histological sections. Anterior tentorial groove not connected with posterior part of tentorium.

\section{Labrum (Figs 1, 14, 15)}

Well developed, but fairly narrow, posteriorly directed, at an angle of approximately $90^{\circ}$ to frontoclypeal surface. Anterior-most part semimembranous (Fig. 1). Fits closely with upper part of mandibles and anterior hypopharynx. Distribution of setae as in Figs 1 and 14.

Musculature (Fig. 5, 7): M 7: M. labroepiparyngalis, well developed, $\mathrm{O}$ : dorsal wall of labrum, I: anterior-most part of epipharynx; M 9: frontoepipharyngalis, strong muscle, $\mathrm{O}$ : anterior frontal region, $\mathrm{I}$ : medially on v-shaped anterior epipharynx. It cannot be fully excluded that this muscle is an anterior component of $\mathrm{M}$ clypeopalatalis (M 43).

Antennae (Figs 1, 3, 14)

Three-segmented, moderately long. Inserted on small, slightly protruding membranous articulatory area (Fig. 1; flat or invaginated in SEMs: Fig. 14). Antennomere II more than twice as long as I. Antennomere III distinctly narrower and shorter than I, with apical seta. Sensorial appendage well developed, inserted apicoventrally on antennomere II.

Musculature (Fig. 5): Mm 1, 2, 4: M. tentorioscapalis anterior, posterior and medialis, $\mathrm{O}$ : flattened dorsal tentorial arm, I: base of antennomere I.

Mandibles (Figs 1, 6, 15)

Symmetrical, moderately long, with slender, serrate apical part. Mesal margin with pointed, hyalinous prostheca. Mola well developed, with minute, posteriorly directed teeth dorsally (Fig. 6). Distinct ventral accessory process present on base of mandible.

Musculature (Figs 6, 7, 8, 10): M 11: M. craniomandibularis internus, very large muscle, $\mathrm{O}$ : dorsal, dorsolateral, lateral, and ventrolateral areas of the head capsule, I: adductor tendon; $\mathrm{M}$ 12: $\mathrm{M}$. craniomandibularis externus, unusually large, O: lateral and dorsal wall of head capsule, with large vertical, anterior component, I: abductor tendon.

\section{Maxillae (Figs 6, 15)}

Inserted in a well developed fossa maxillaris. Articulatory membrane present. Cardo and stipes connected by a hinge. Separate galea absent. Mala rounded, fairly large, semimembranous, with a fringe of long hairs (Fig. 15). Palp three-segmented inserted on a flat, inconspicuous palpifer. Palpomere I very short, II about as long as broad. Antennomere III longer than II, slightly narrowed apically.

Maxillary musculature (Figs 6, 7, 10): M 15: M. craniocardinalis, $\mathrm{O}$ : ventrolaterally from the hind margin of the head capsule, immediately lateral to the posterior tentorial arms, I: laterally on a small condyle of the cardo by means of a tendon; $\mathrm{M}$ 17: $\mathrm{M}$. tentoriocardinalis, $\mathrm{O}$ : tentorial bridge and posterior tentorial arm, I: mesally on cardo; M 18: M. tentoriostipitalis, composed of three subcomponents, M 18a, O: tentorial bridge and posterior tentorial arm, I: ventral surface of stipes; M 18b, O: tentorial bridge and posterior tentorial arm, I: mesal edge of stipes; M. 18c, a small bundle, distinctly separated from M 18b, $\mathrm{O}$ : posterior edge of hypopharynx, I: laterally on ventral surface of anterior part of stipes; M 19: M. craniolacinialis, one large bundle, O: laterally from head capsule, I: base of lacinia by means of a tendon; M 22, 23: M. stipitopalpalis externus and internus, $O$ : mesal side of stipes, I: base of maxillary palp.

\section{Labium (Figs 14, 15)}

Submentum and mentum distinctly separated, both approximately quadrangular and sclerotized, inserted between maxillary grooves. Prementum well developed, fairly broad, anterolaterally covered with very short spines. Anterior margin straight, without ligula. Palps two-segmented.

Musculature (Figs 7, 10): M. 28a: M. submentopraementalis, $\mathrm{O}$ : laterally on posterior submentum, below origin of posterior tentorial arm, I: posterior margin of prementum; M. 28b: submentomentalis, O: laterally on posterior submentum, together with $28 \mathrm{a}$, I: laterally on surface of mentum; M 29: M. tentoriopraementalis infe- 

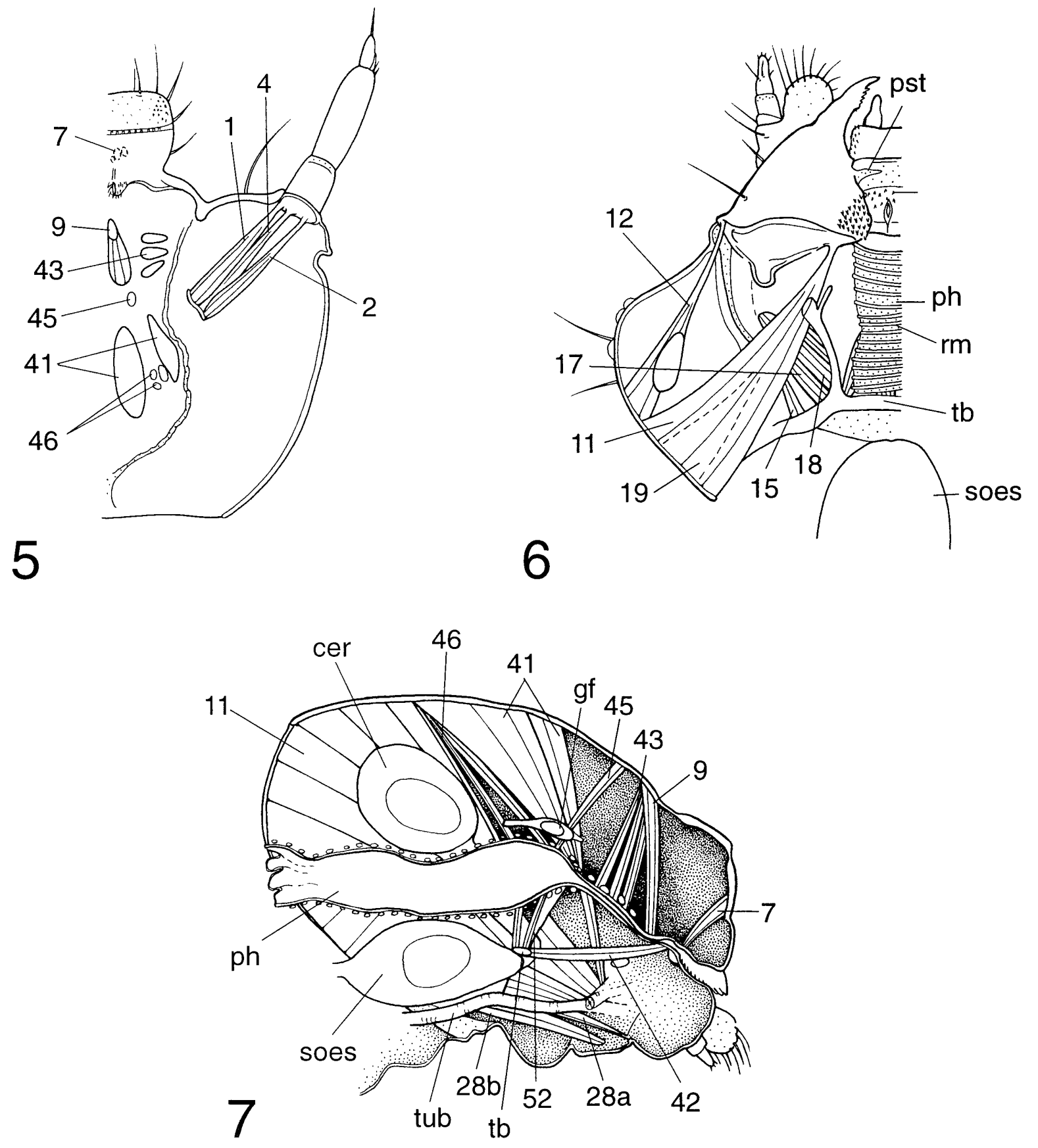

Figs 5-7: 5 - Larval head of Sphindus americanus, horizontal section, dorsal half; 6 - horizontal section, ventral half; 7 - sagittal section. Abbreviations: cer - cerebrum, gf - frontal ganglion, ph - pharynx, pst - prostheca, rm - ring musculature, soes - suboesophageal ganglion, tb - tentorial bridge, tub - tube-like salivary glands, 1, 2, 4 - antennal muscles, 7 - M. labroepipharnygalis, 9 - M. frontoepipharyngalis, 11 - M. craniomandibularis internus, 12 - M. craniomandibularis externus, 15 - M. craniocardinalis, 17 - M. tentoriocardinalis, 18 - M. tentoriostipitalis, 19 - M. craniolacinialis, 28 - M. submentopraementalis, 41 - M. frontohypopharyngalis, 42 - M. tentoriohypopharyngalis medialis, 43 - M. clypeopalatalis, 45 - M. frontobuccalis anterior, 46 - M. frontobuccalis posterior, 52 - M. tentoriopharyngalis.

rior, absent; M. 30: M. tentoriopraementalis superior, absent; M 34: Mm. praementopalpalis externus, absent.

Epipharynx (Figs 5, 8)

Anterior part of ventral side of labrum completely membranous, with lateral group of short bristles, separated from posterior part by a transverse row of small spines. Posterior epipharynx V-shaped in cross section, with deep U-shaped median groove, forming narrow lateral grooves with upper sides of mandibles (Fig. 8). Posterior part of epipharynx not fused with hypopharynx anterior to anatomical mouth, prepharyngeal tube absent.

Musculature (Figs 5, 7, 8): M 43: M. clypeopalatalis, composed of three bundles, which are separated by trans- 
TABLE 1. Character state matrix. ? = character states unknown.

\begin{tabular}{lllllllllllllllllllllll}
\hline & 1 & 2 & 3 & 4 & 5 & 6 & 7 & 8 & 9 & 10 & 11 & 12 & 13 & 14 & 15 & 16 & 17 & 18 & 19 & 20 & 21 & 22 \\
\hline Ochthebius & 1 & 0 & 0 & 0 & 0 & 0 & 0 & 0 & 0 & 0 & 0 & 0 & 0 & 0 & 0 & 0 & 0 & 0 & 1 & 0 & 0 & 0 \\
Derodontus & 1 & 0 & 0 & 0 & 0 & 1 & 0 & 0 & 0 & 1 & 0 & 0 & 1 & 0 & 0 & 0 & 0 & 0 & 0 & 0 & 0 & 0 \\
Elateroides & 0 & 1 & 0 & 2 & 1 & 0 & 0 & 0 & 1 & 0 & 0 & 0 & 0 & 1 & 0 & 1 & 0 & 0 & 1 & 1 & 0 & 1 \\
Sphindus & 0 & 1 & 0 & 0 & 1 & 1 & 0 & 0 & 0 & 1 & 0 & 1 & 0 & 2 & 1 & 1 & 0 & 0 & 1 & 1 & 0 & 1 \\
Ericmodes & 1 & 1 & 0 & 1 & 1 & 1 & 0 & 0 & 0 & 1 & 0 & 1 & 1 & 2 & 0 & 1 & 0 & 1 & 1 & 1 & 0 & 1 \\
Zeonidicola & 1 & 1 & 0 & 1 & 1 & 0 & 0 & 1 & 1 & 0 & 0 & 1 & 0 & 2 & 0 & 1 & $?$ & 1 & 1 & 1 & 0 & 1 \\
Mycetina & 1 & 1 & 1 & 1 & 1 & 0 & 0 & 0 & 1 & 0 & 1 & 1 & 0 & 2 & 1 & 1 & 1 & 1 & 1 & 1 & 0 & 1 \\
Oryzaephilus & 5 & 1 & 0 & 1 & 1 & 0 & 0 & 0 & 0 & 1 & 0 & 1 & 0 & 2 & 1 & 1 & 0 & 1 & 1 & 1 & 0 & 1 \\
Silvanus & 5 & 1 & 0 & 1 & 1 & 0 & 0 & 0 & 0 & 1 & 0 & 1 & 0 & 2 & 1 & 1 & 0 & 1 & 0 & 1 & 0 & 1 \\
Coccinella & 2 & 1 & 1 & 1 & 1 & 0 & 0 & 1 & 1 & 0 & 1 & 1 & 0 & 2 & 0 & 1 & 1 & 1 & 1 & 1 & 0 & 1 \\
Glischrochilus & 2 & 0 & 1 & 0 & 1 & 0 & 0 & 0 & 0 & 0 & 1 & 1 & 2 & 2 & 1 & 1 & 0 & 1 & 1 & 1 & 2 & 1 \\
Collops & 4 & 0 & 1 & 1 & 1 & 0 & 1 & 1 & 2 & 0 & 1 & 1 & 0 & 2 & 0 & 0 & 1 & 1 & 1 & 1 & 2 & 1 \\
Phycosecis & 4 & 3 & 1 & 2 & 1 & 0 & 1 & 1 & 1 & 0 & 1 & 1 & 0 & 2 & 0 & 0 & 1 & 2 & 1 & 1 & 1 & 1 \\
Calytis & 3 & 2 & 1 & 2 & 1 & 0 & 1 & 1 & 1 & 0 & 1 & 1 & 2 & 2 & 0 & 0 & 1 & 2 & 1 & 1 & 1 & 1 \\
Lemidia & 3 & 2 & 2 & 2 & 1 & 0 & 1 & 1 & 1 & 0 & 1 & 1 & 2 & 2 & 0 & 0 & 1 & 2 & 1 & 1 & 1 & 1 \\
Bitoma & 5 & 1 & 3 & 1 & 1 & 0 & 0 & 0 & 1 & 0 & 0 & 0 & 0 & 2 & 1 & 1 & 0 & 1 & 0 & 1 & 0 & 1 \\
Pyrochroa & 5 & 1 & 3 & 1 & 1 & 0 & 0 & 0 & 1 & 0 & 0 & 0 & 0 & 2 & 1 & 1 & 0 & 1 & 0 & 0 & 0 & 1 \\
Altica & 0 & 1 & 0 & 1 & 1 & 0 & 0 & 1 & 1 & 0 & 0 & 0 & 0 & 2 & 0 & 0 & 1 & 0 & 1 & 0 & 0 & 1 \\
\hline & & & & & & & & & & & & & & & & & &
\end{tabular}

verse muscles, $\mathrm{O}$ : anterior frontal region, I: paramedially on posterior epipharynx.

Hypopharynx (Figs 6, 8, 15)

Anterior part not clearly separated from prementum, with distinct membranous lateral lobes that are covered with serrate scale-like structures (Fig. 15). Posterolateral walls connected by extremely strong, internal transverse bar (Fig. 8).

Musculature (Figs 6, 7, 10): M 41: M. frontohypopharyngalis, V-shaped in cross section, composed of two large components, $\mathrm{O}$ : mesal and lateral area of posterior frons, I: posterolaterally on hypopharynx by means of a very strong tendon; $\mathrm{M} 42 \mathrm{~m}$ : $\mathrm{M}$. tentoriohypopharyngalis medialis, $\mathrm{O}$ : tentorial bridge, $\mathrm{I}$ : posteromedially on hypopharynx; M 42l: M. tentoriohypopharyngalis lateralis, absent.

A transverse hypopharyngeal muscle connecting posteriorly directed apodemes or the lateral hypopharyngeal walls is absent.

\section{Pharynx (Figs 6, 7, 10)}

Fairly thin, lumen strongly narrowed, star-shaped in cross section.

Musculature (Figs 5-7, 10): M 45: M. frontobuccalis anterior, O: frons, anterior to $\mathrm{M} \mathrm{41,} \mathrm{I:} \mathrm{dorsally} \mathrm{on} \mathrm{phar-}$ ynx, immediately posterior to the anatomical mouth; $M$ 46: M. frontobuccalis posterior, three thin bundles, $O$ : posterior frons, between the two components of $\mathrm{M} \mathrm{41,} \mathrm{I:}$ dorsolaterally on pharynx; M 51: M. verticopharyngalis, absent; M 52: M. tentoriopharyngalis, four thin bundles, $\mathrm{O}$ : tentorial bridge, I: ventrolaterally on posterior pharynx.

A well developed ring musculature is present over the whole length of the pharynx (Figs 6,7).

Cerebrum and suboesophageal ganglion (Figs 6, 7, 10, 12, 13)

Cerebrum and suboesophageal ganglion moderately sized in relation to size of head capsule, not elongated, not extending posteriorly into the prothorax.
Glands (Figs 7, 10)

Paired gland-like ducts originate in the anterior thorax. The exact distal orifice could not be identified.

Fat body (Fig. 10)

Fairly extensive parts of fat body located in posterior part of head capsule.

Foregut

Proventriculus absent.

\section{Ericmodes}

Head capsule (Figs 2, 4, 16; external features see also Ślipiński, 1998)

Internal skeletal structures (Fig. 11).

Posterior arms arise immediately anterior to foramen occipitale, connected by strongly broadened, plate-like tentorial bridge. Dorsal arms present but very flat and unsclerotized, attached to head capsule by fibrillar structures. Anterior arms not identified in histological sections, extremely thin or absent. Anterior tentorial grooves not connected with posterior tentorium.

Labrum (Figs 2, 4, 16)

Fairly broad, almost vertical. Distribution of setae on dorsal surface as in Fig. 16. Anterior margin with a group of four setae in a transverse row, tip with a densely arranged group of shorter setae, and a semicircular dense field of microtrichiae.

Musculature (Fig. 9): M 7: M. labroepipharyngalis, not clearly identified, probably present; $M$ 9: $M$. frontoepipharyngalis, strong muscle, especially in late instar larvae, $\mathrm{O}$ : frons, anterior to $\mathrm{M} 45, \mathrm{I}$ : medially on $\mathrm{V}$-shaped, anterior epipharynx.

M 9 and the anterior component of M. clypeopalatalis are almost parallel and similar in the early instars (Fig. 9). However, both muscles can be very clearly distinguished in mature larvae.

Antennae (Fig. 2; external features see Ślipiński, 1998) 

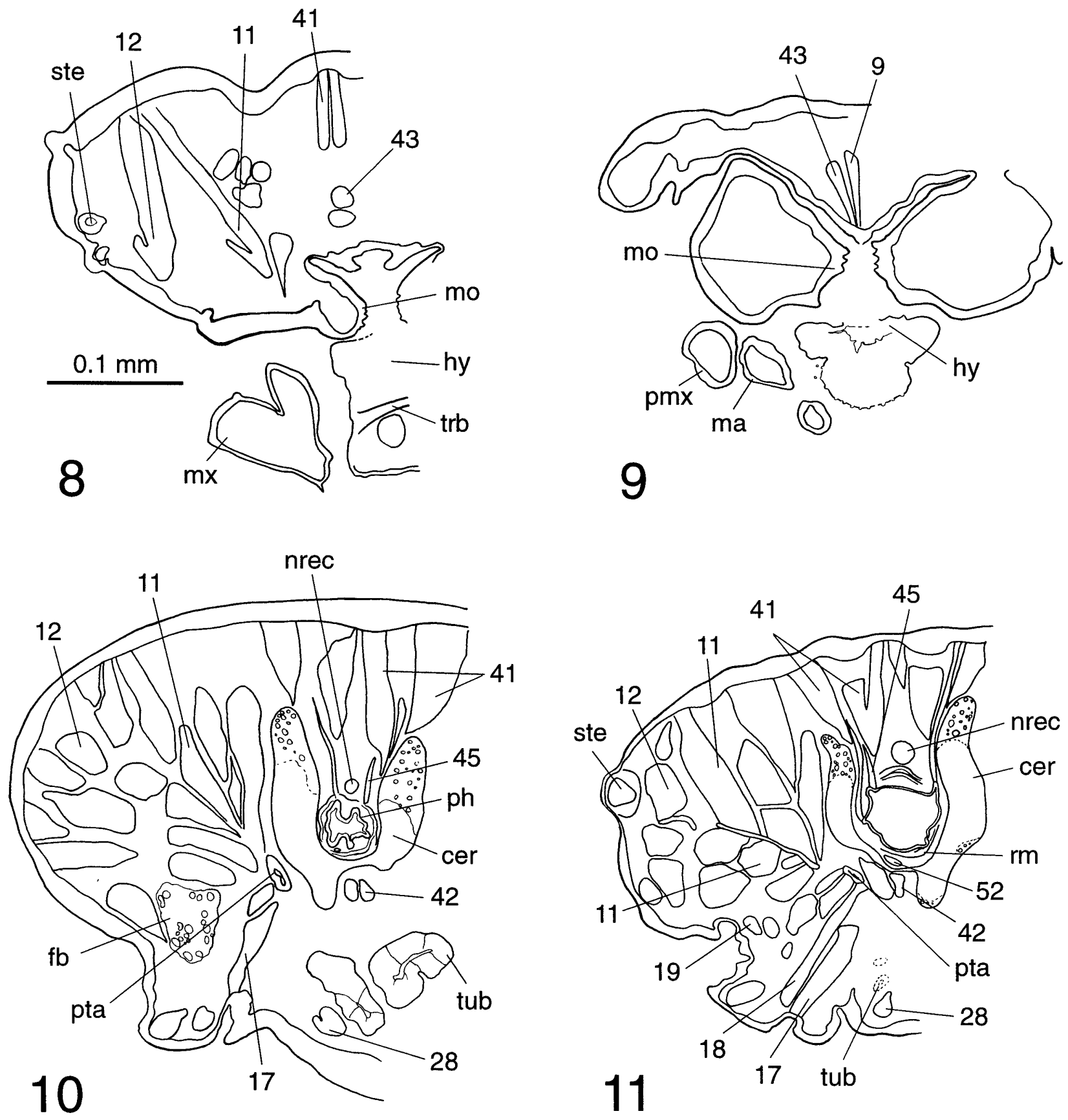

Figs 8-11: 8 - Cross sections of epipharyngeal region of Sphindus americanus . 9 - Ericmodes sp; 10 - anterior pharyngeal region of Sphindus americanus ; 11 - Ericmodes sp. Abbreviations: cer - cerebrum, fb - fat body, hy - hypopharynx, ma - mala, mo mola, $\mathbf{m x}$ - maxialla, nrec - nervus recurrens, $\mathbf{p h}$ - pharynx, $\mathbf{p m x}$ - palpus maxillaris, pta - posterior tentorial arm, $\mathbf{r m}$ - ring muscle, ste - stemmata, trb - transverse bar, tub - tube-like salivary glands, 9 - M. frontoepipharyngalis, 11 - M. craniomandibularis internus, 12 - M. craniomandibularis externus, 17 - M. tentoriocardinalis, 18 - M. tentoriostipitalis, 19 - M. craniolacinialis, 28 - M. submentopraementalis, 41 - M. frontohypopharyngalis, 42 - M. tentoriohypopharyngalis medialis, 43 - M. clypeopalatalis, 45 - M. frontobuccalis anterior, 46 - M. frontobuccalis posterior, 52 - M. tentoriopharyngalis.

Musculature: $\mathrm{Mm}$ 1, 2, 4: $\mathrm{Mm}$. tentorioscapalis anterior, posterior, and medialis, moderately developed muscles, O: dorsal wall of head capsule, immediately close to attachment of dorsal tentorial arm, I: base of antennomere I.
Mandibles (Fig. 11; external features see Ślipiński, 1998)

Musculature: M 11: M. craniomandibularis internus, largest muscle in larval head, O: dorsolaterally from anterior head capsule, dorsolaterally, laterally, and ventrolaterally from posterior head capsule, I: adductor tendon; M 12: M. craniomandibularis externus, composed of four 
large bundles, $\mathrm{O}$ : laterally, ventrolaterally, and dorsolaterally from head capsule, dorsolateral subcomponent attached posterior to posterior row of stemmata, I: abductor tendon.

Maxillae (Fig. 16; external features see also Ślipiński, 1998)

Not closely connected with labium, lateral mobility fully retained. Apex of mala with several sharply pointed teeth and a subapical spine (Fig. 16).

Musculature (Fig. 11): M 15: M. craniocardinalis, two subcomponents, $\mathrm{O}$ : immediately close to posterior margin of head capsule, dorsolaterally and ventrolaterally between attachment areas of M 19, I: small process of cardinal base; M 17: M. tentoriocardinalis, O: broad tentorial bridge and upper part of posterior tentorial arm, I: ventral surface of cardo; M 18: M. tentoriostipitalis, very large muscle, composed of three subcomponents, M 18a, $O$ : broad tentorial bridge and upper part of posterior tentorial arm, mesal to M 17, I: ventral surface of stipes; $M$ $18 \mathrm{~b}, \mathrm{O}$ : tentorial bridge and upper part of posterior tentorial arm, I: anterior mesal edge of stipes; M 18c, fairly large, not clearly separated from M 18b, O: ventrally from posterior hypopharynx, I: ventrolateral surface of anteriormost part of stipes; M 19: M. craniolacinialis, two well developed bundles, $\mathrm{O}$ : ventrolaterally from head capsule, separated by ventrolateral subcomponent of $\mathrm{M}$ 15, I: base of mala; M 22, 23: M. stipitopalpalis externus and internus, two distinct bundles, $O$ : ventrally and ventromesally from stipes, I: base of maxillary palp.

A short transverse muscle with unknown homology connects the ventral and lateral edges of the anterior stipes.

Labium (Fig. 16; external features see Ślipiński, 1998)

Musculature (Fig. 11): M. 28: M. submentopraementalis, large muscle, $\mathrm{O}$ : posterior submentum, close to median line, I: ventrolaterally on posterior margin of prementum

A second, thin labial muscle is medially attached to the posterior premental margin. The origin could not be identified in the available microtome series. It is likely that it arises from the tentorial bridge, together with $\mathrm{M} 18 \mathrm{~b}$. This would imply homology with $\mathrm{M}$. tentoriopraementalis inferior (M 29). M. 30: M. tentoriopraementalis superior, absent; M 34: Mm. praementopalpalis ext., absent.

Epipharynx (Fig. 9)

Anterior epipharynx distinctly V-shaped in cross section. Posterior epipharynx, molar part of mandibles, and posterior part of hypopharynx form an X-shaped preoral chamber. Short, closed prepharyngeal tube formed by lateral fusion of posteriormost epipharnyx and hypopharynx.

Musculature (Fig. 9): M 43: M. clypeopalatalis, three moderately sized bundles, separated by large transverse muscles, $\mathrm{O}$ : successively from anterior frontoclypeal region, I: anterior component immediately lateral to $M 9$ (Fig. 9), other bundles successively on posterior epipharnyx.
Hypopharynx (Figs 9, 16)

Anterior hypopharynx with a very dense field of erect stiff bristles. Lateral walls connected by a transverse, extremely strong internal bar. Posterior hypopharynx forms ventral part of preoral chamber and prepharyngeal tube.

Musculature (Fig. 11): M 41: M. frontohypopharyngalis, $\mathrm{V}$-shaped in cross section, $\mathrm{O}$ : large parts of the posteriorly extended frons, I: posterolaterally on hypopharynx by means of a strong tendon; M $42 \mathrm{~m}$ : $\mathrm{M}$. tentoriohypopharyngalis medialis, fairly strong pair of bundles, $\mathrm{O}$ : tentorial bridge, $\mathrm{I}$ : posteromedially on hypopharynx; M 421: M. tentoriohypopharyngalis lateralis, absent.

The transverse hypopharyngeal muscle is absent.

Pharynx (Fig. 11)

Fairly wide in diameter, but lumen very narrow, with narrow ventrolateral, lateral and dorsolateral folds.

Musculature (Fig. 11): M 45: M. frontobuccalis anterior, one moderately sized muscle, $\mathrm{O}$ : anterior frontal region, mesal to anteriormost part of $\mathrm{M} \mathrm{41}$, I: dorsolaterally on pharynx, immediately posterior to the frontal ganglion and anatomical mouth; $M$ 46: $M$. frontobuccalis posterior, several thin and flat parallel bundles, $\mathrm{O}$ : posterior frons, between and lateral to bundles of $\mathrm{M} \mathrm{41,} \mathrm{I:} \mathrm{dor-}$ solateral folds of pharynx; M 51: M. verticopharyngalis, absent; M 52: M. tentoriopharyngalis, composed of two subcomponents, M 52a, three pairs of fairly large bundles, $\mathrm{O}$ : proximal part of posterior tentorial arms and tentorial bridge, I: ventrolaterally and laterally on posterior pharynx, M 52b, one pair of muscles, O: tentorial bridge, I: ventrally on anterior pharynx, immediately posterior to anatomical mouth.

A well developed series of ring muscles is present over the whole length of the pharynx.

Cerebrum and suboesophageal ganglion (Fig. 11)

Fairly large in relation to head size and distinctly elongated. Posterior part of cerebrum shifted into prothorax in early instars.

Glands (Fig. 11)

Paired gland-like ducts originate in the prothorax. Thin in early instar larvae, rather massive in late instars. Distal orifice not clearly identified in sections, probably located on anteriormost hypopharynx.

Fat body

Almost completely absent from head capsule.

Fore gut

Oesophagus strongly twisted posterior to pharynx. Fairly wide, with thin wall and well developed ring muscles. Posterior oesophagus with star-shaped constriction with ring muscles and longitudinal muscles. Proventriculus absent. 


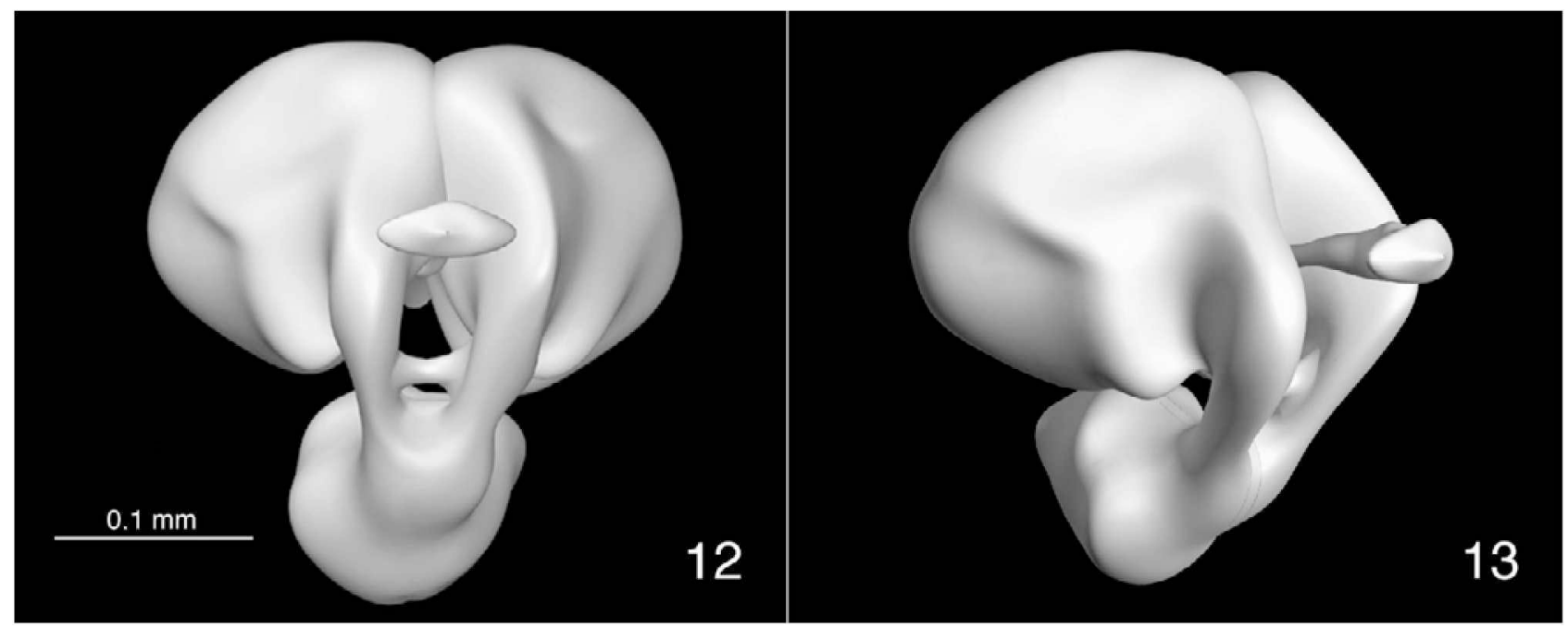

Figs 12-13: Three-dimensional computer reconstruction of the cerebrum and suboesophageal ganglion of Sphindus americanus (reconstruction with ALIAS wavefront). 12 - anterior; 13 - anterolateral view.

\section{PHYLOGENETICALLY RELEVANT CHARACTERS (TABLE 1)}

1. Gula: (0) absent; (1) short, weakly sclerotized or semimembranous, inserted between posterior tentorial grooves, not clearly separated from submentum; (2) short, sclerotized, inserted between posterior tentorial grooves, completely fused with submentum; (3) moderately or strongly elongated, parallel-sided, sclerotized and pigmented (4) moderately elongated, parallel-sided, unpigmented; (5) short and transverse, diverging posteriorly, inserted between gular ridges posterior to tentorial bridge

The gula is absent in larvae of Sphindus, Elateroides (Lymexylidae) and Altica (Chrysomelidae). A short, semimembranous gula is present between the posterior tentorial grooves in larvae of Ericmodes (Ślipiński, 1998), in the hypognathous larvae of Mycetina (Burakowski, 1997, Fig. 4; pers. obs.) and in larvae of many groups with a subprognathous head (e.g. Cavoganthidae, Hydraenidae, Derodontidae). The gula is short, inserted between the posterior tentorial grooves, sclerotized and fused with the submentum in larvae of Glischrochilus. A quadrangular or elongated, parallel-sided sclerotized gular plate is present in larvae of Calytis, Temnoscheila (Trogossitidae) and Lemidia (Cleridae). It is distinctly present but unpigmented in larvae of Phycosecis and Melyridae. The gula is broad, sclerotized, inserted between gular ridges, and diverging posteriorly in prognathous larvae of Cucujoidea (e.g. Silvanidae) and Tenebrionoidea (e.g. Pyrochroidae, Colydiidae). It is apparent that this character is highly variable, associated with feeding habits and different degrees of hypo- or prognathism.

2. Hypostomal rods: (0) absent; (1) present, posteriorly diverging; (2) present, parallel-sided; (3) present, posteriorly converging
Hypostomal rods are absent in larvae of Elateroides, Glischrochilus, and Collops. They are diverging in most larvae of Cucujoidea (e.g. Sphindus, Ericmodes, Mycetina) and Tenebrionoidea (e.g. Bitoma, Pyrochroa), parallel sided in most larvae of Cleroidea (e.g. Calytis, Lemidia) and converging in larvae of Phycosecis.

3. Posterior tentorial arm: (0) connected with tentorial bridge; (1) posterior arms shifted anteriorly, disconnected from tentorial bridge; (2) part of elongated gular ridges, connected with ventral prepharyngeal wall; (3) tentorial bridge shifted anteriorly, gular ridges present posterior to bridge

The proximal and distal parts of the posterior tentorial arms and the tentorial bridge form a continuous structure close to the foramen occipitale in larvae of Sphindus, Ericmodes, Elateroides, Oryzaephilus, Silvanus (Silvanidae) and Altica. The same, presumably plesiomorphic character state is found in larvae of most other groups of Coleoptera (e.g. Beutel, 1993, 1995, 1996; Beutel \& Molenda, 1997). A tentorium with the posterior arms clearly separated from the tentorial bridge is found in larvae of Trogossitidae, Phycosecidae, Nitidulidae, Endomychidae and Coccinellidae, and also in larvae of most groups of Elateriformia (Beutel, 1995). The posterior tentorial arms are part of strongly elongated gular ridges and anteriorly connected with the prepharynx in larvae of Lemidia. The tentorial bridge and posterior arms are distinctly shifted anteriorly in larvae of Pyrochroa and Bitoma. These larvae possess more or less well developed gular ridges (shallow in Pyrochroa) posterior to the posterior tentorial grooves.

4. Dorsal tentorial arm: (0) distinct; (1) unsclerotized and strongly flattened; (2) absent

The dorsal tentorial arm is fairly well developed in larvae of Sphindus and Glischrochilus and serves as an attachment area for the antennal muscles. A well developed dorsal arm is also found in larvae of most other 
groups of Coleoptera (Beutel, 1995, 1999; Beutel \& Molenda, 1997; Beutel et al., 1999). The dorsal arm is unsclerotized, flattened and more or less distinctly folded in larvae of Ericmodes, in larvae of most other cucujoid groups, and also in larvae of Pyrochroa, Bitoma and Altica. The dorsal arm is absent or extremely thin and disconnected from the head capsule in larvae of Lymexylidae and Cleroidea. A reduced dorsal arm is also a characteristic feature of larvae of most groups of Elateriformia (Beutel, 1995). As there is a continuum in the reduction of this structure, it is difficult to define it as distinct character states.

5. Anterior tentorial arm: (0) distinct; (1) absent or at least obsolete and disconnected from posterior tentorium

The anterior tentorial arms are absent or strongly reduced and disconnected from the posterior tentorium in all cucujiform larvae examined. They are never the origin of antennal muscles as in many groups of Staphylinoidea (Beutel \& Molenda, 1997). The anterior arms are thin but sclerotized and distinct in larvae of Pyrochroa. However, a connection with the posterior arms is not recognizable and apparently absent. Well developed anterior arms are present in most groups of Coleoptera such as Adephaga (Beutel, 1993), Myxophaga (Beutel et al. 1999), Hydrophiloidea (Beutel 1999), Staphylinoidea (Beutel \& Molenda, 1997), Nosodendridae, and Derodontidae (Beutel 1996).

6. Orientation of labrum: (0) continuous with dorsal wall of head capsule, almost horizontal; (1) distinctly inclined, almost vertical

A labrum, which is posteriorly directed at an angle of about $90^{\circ}$ to the frontoclypeal surface, is present in larvae of Sphindus. A similar condition is found in larvae of Ericmodes (Fig. 4), and in those of other groups of Coleoptera such as Derodontus (Derodontidae) and Sepedophilus (Staphylinidae). Especially in larvae of Sphindus and Sepedophilus, labrum, mandibles and hypopharynx together form a preoral working space, which can be tightly closed. A labrum that is more or less horizontal in relation to the clypeus and frons is present in larvae of other groups of Cucujoidea, Cleroidea and Tenebrionoidea (e.g. Mycetina, Silvanus, Phycosecis, Lemidia, Calytis, Pyrochroa, Bitoma, Altica).

7. Orientation of antenna: (0) parallel to longitudinal body axis; (1) angle of at least $30^{\circ}$ to longitudinal body axis

Anterolaterally directed antennae are present in larvae of Sphindus and Ericmodes, and in other larvae of Cucujoidea and Tenebrionoidea (e.g. Nitidulidae, Silvanidae, Colydiidae, Pyrochroidea, Pythidae; Lawrence, 1991; pers. obs.). The orientation of antennae parallel to the body axis and a transverse basal line of antennomere $\mathrm{I}$ is a characteristic, potentially synapomorphic feature of cleroid larvae (Lawrence, 1991).

8. Mandibular mola: (0) present; (1) absent

A mola, which is well developed and set with tiny spines is present in larvae of Sphindidae and Protocucujidae, and larvae of most other groups of Cucujoidea and
Tenebrionoidea (Lawrence, 1991). A mola is absent from larvae of the cucjoid families Coccinellidae, Cavognathidae, Cerylonidae (part.; present Murmidiinae and Euxestinae), Corylophidae (part.), Phalacridae (part.), Erotylidae (part.) (Lawrence, 1991), from larvae of several groups of Tenebrionoidea (e.g. Mordellidae, Tetratomidae part; Lawrence, 1991), from all larvae of Cleroidea (Lawrence, 1991), and from larvae of Chrysomelidae (Lawson, 1991). Loss of the mandibular mola has occured many times independently and is correlated in most cases with predacious habits (e.g. Adephaga, Staphylininae, Histeroidea, Hydrophiloidea, Elateriformia part.; Beutel, 1993, 1995, 1999).

9. Mandibular prostheca: (0) present; (1) absent

A pointed, hyalinous prostheca is present in larvae of Sphindidae, and in many other groups of Cucujoidea (e.g. Rhizophagidae, Boganiidae, Phloeostichidae; Lawrence, 1991). It is largely reduced in mature larvae of Ericmodes but distinct in the earlier stages (Ślipiński, 1998). It is therefore coded as $(0)$ for this genus. The prostheca is absent from larvae of Cleroidea, Cavognathidae, Coccinellidae, Tenebrionoidea (e.g. Pyrochroa, Bitoma; Lawrence, 1991) and Chrysomelidae (Lawson 1991). A modified, complex prostheca is present in most larvae of Nitidulidae. The character is scored as $(0)$ for this family.

10. Ventral accessory process of mandibular base: (0) present; (1) absent

A ventral accessory process of the mandibular base is present in larvae of Sphindidae and Protocucujidae and several other groups of Coleoptera (e.g. Derodontidae, Silvanidae; Lawrence, 1991; Burakowski \& Ślipiński, 1987; Ślipiński, 1998; pers. obs.).

11. Maxilla and labium: (0) separate or moderately coadapted; (1) maxillolabial complex

A maxillolabial complex with restricted lateral mobility of the maxillae with a poorly developed articulatory membrane is present in larvae of Cleroidea, Nitidulidae, Coccinellidae and Endomychidae. It moves mainly vertically. A similar condition is found in most larvae of Elateriformia (Beutel, 1995). A maxillolabial complex as defined above is absent in larvae of Sphindidae, Protocucujidae and larvae of other groups of Cucujiformia (Lawrence, 1991). Moderately coadapted ventral mouthparts of some cucujoid groups (e.g. Sphindidae; coded as 0 in this study) are referred to as a maxillolabial complex by Lawrence (1991). The phylogenetic significance of this character is weakened by the fact that the formation of a maxillolabial complex occurs gradually.

12. Origin of M. tentoriostipitalis: (0) exclusively from posterior tentorial arm and tentorial bridge; (1) anterior subcomponent originates from ventral hypopharynx

The origin of an anterior bundle of M. tentoriostipitalis (M 18c) from the ventral wall of the prephagyngeal tube or from the posterior edge of the hypopharynx is an unusual feature which is found in larvae of Sphindus, Ericmodes, Zeonidicola, Mycetina, Coccinella, Silvanus, Oryzaephilus and Cleroidea. M $18 \mathrm{c}$ is thin and isolated from $\mathrm{Mm} 18 \mathrm{a}$ and $\mathrm{b}$ in larvae of Sphindus, moderately 

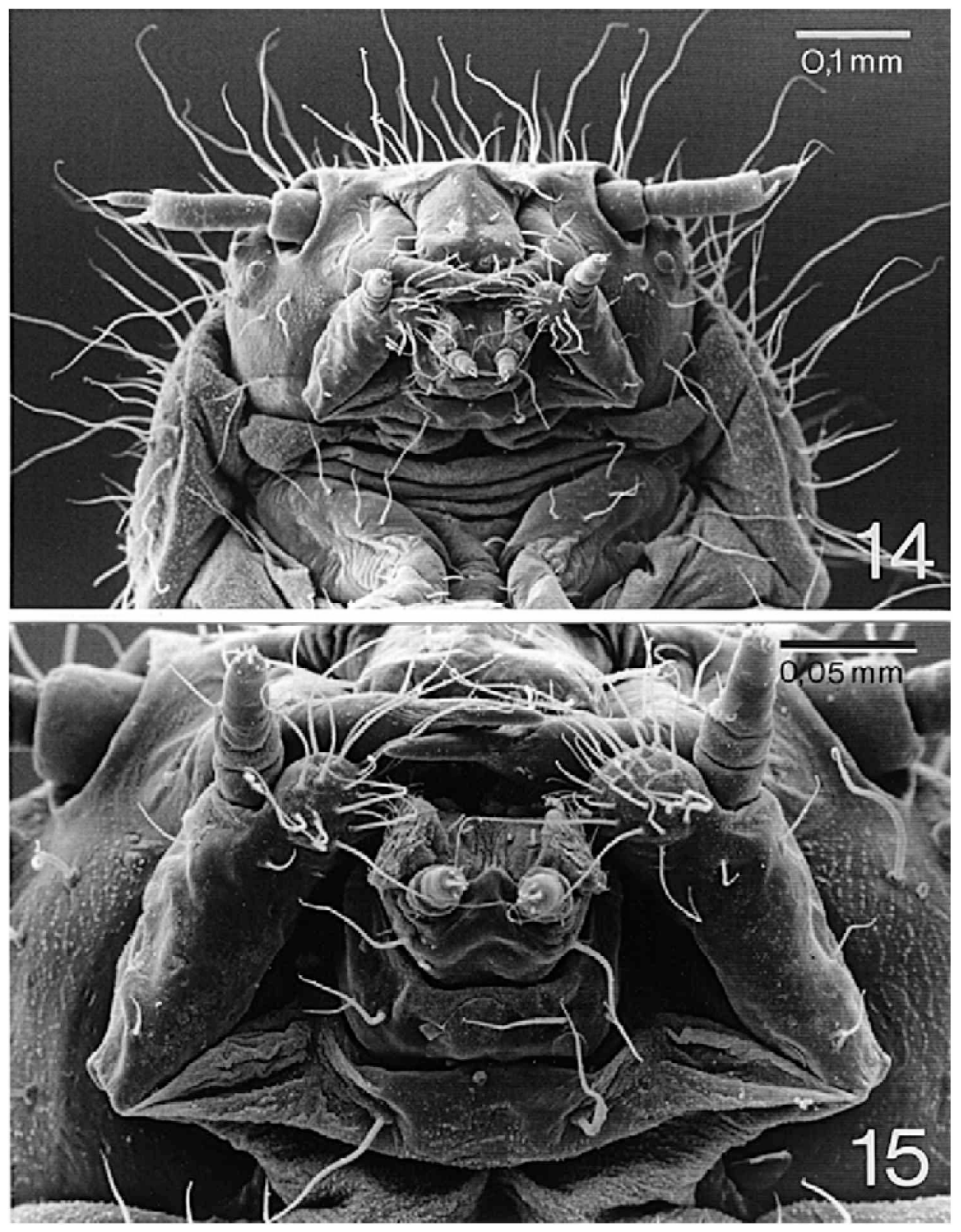

Figs 14-15: SEM micrographs of Sphindus americanus. 14 - ventral view of head; 15 - frontal view of mouthparts.

sized in larvae of Ericmodes, and large in the other larvae listed above. A hypopharyngeal component of $M$. tentoriostipitalis had previously been described only for lampyrid larvae (Beutel, 1995).

13. Tentorial bridge: (0) not distinctly broadened; (1) strongly broadened, plate-like; (2) thin and tendon-like

A distinctly broadened, plate-like tentorial bridge is presumably a derived feature found in larvae of Ericmodes but not in other larvae of Cucujoidea or Cleroidea. It is an extensive attachment area of $\mathrm{Mm}$. tentoriocardinalis and-stiptalis. The bridge is also distinctly broadened in larvae of Derodontus, whereas it is very thin and tendon-like in larvae of Cleridae and Trogossitidae.

14. Galea and lacinia: (0) separate; (1) partly fused; (2) absent
Absence of a separate galea is an apomorphic condition found in almost all larvae of Cucujiformia excl. Lymexylidae. Galea and lacinia are very closely attached to each other but still recognizable as separate structures in larvae of Elateroides. A distinctly cleft mala, as present in some larvae of Erotylidae (Lawrence 1991; McHugh pers. comm.: Megalodacninae), is probably not a plesiomorphy but a secondarily derived feature.

15. M. tentoriopraementalis inferior: (0) present; (1) absent

M. tentoriopraementalis inferior is probably present in larvae of Ericmodes, and widely in larvae of Coleoptera (Beutel, 1993, 1996, 1999; Beutel \& Molenda, 1997), but absent from larvae of Sphindus, Silvanus, Oryzaephilus, Glischrochilus, Mycetina, Bitoma and Pyrochroa. 


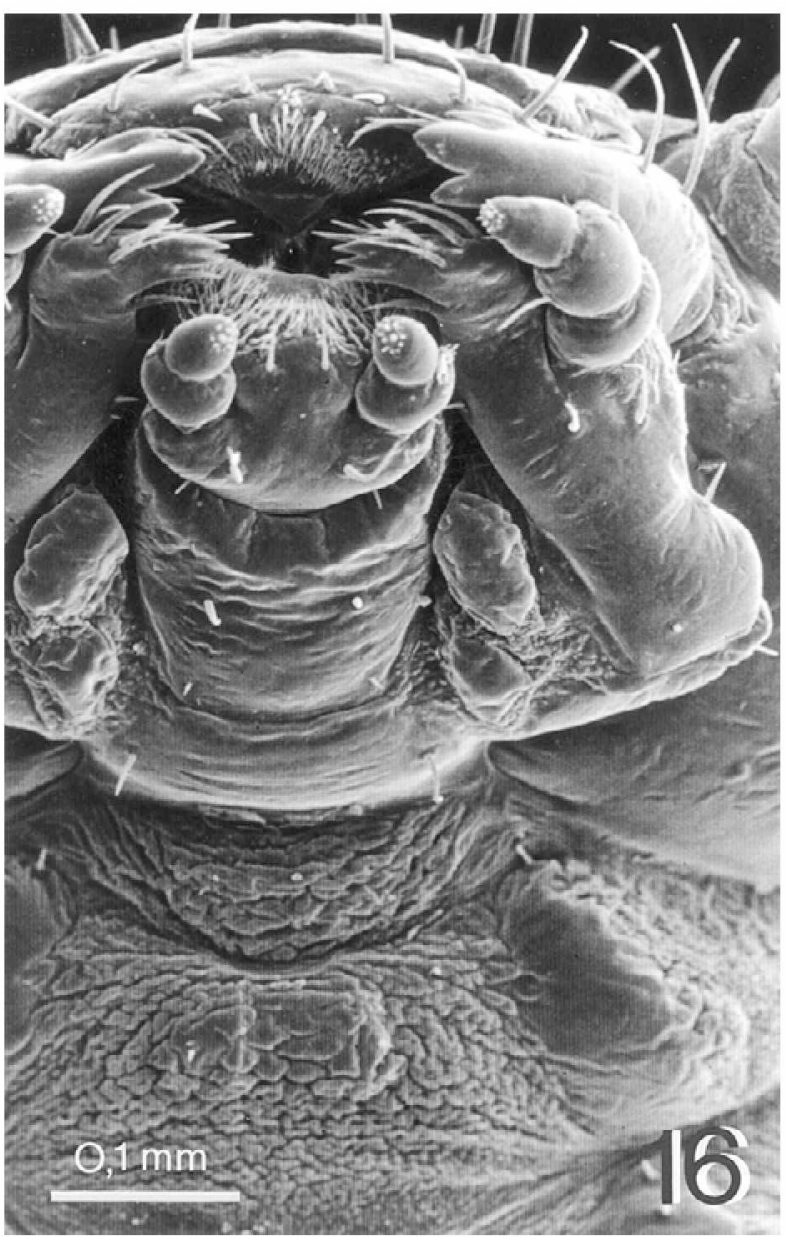

Fig. 16. SEM micrographs of Ericmodes, frontal view of mouthparts.

16. M. tenoriopraementalis superior: (0) present; (1) absent

M. tentoriopraementalis superior is absent from larvae of Ericmodes, Sphindus, Zeonidicola, Elateroides, Mycetina, Silvanus, Oryzaephilus, Coccinella, Bitoma and Pyrochroa. It is present in larvae of Cleroidea, Altica (atypical origin and insertion), and most other larvae of Coleoptera (Beutel, 1993, 1996, 1999; Beutel \& Molenda, 1997).

17. M. frontoepipharyngalis: (0) present, V-shaped, inserted on median edge of anterior epipharynx; (1) absent

A characteristic, $\mathrm{V}$-shaped frontoepipharyngeal muscle, which is medially inserted on a more or less well developed median ridge of the anterior epipharynx, is present in larvae of Sphindus, Ericmodes, Elateroides, Glischrochilus, Silvanus, Oryzaephilus, Bitoma and Pryrochroa, and larvae of many other groups of Coleoptera (e.g. Sepedophilus, Derodontus). The muscle is absent or transformed into a paramedian, vertical frontobuccal muscle in cleroid larvae and is also absent from larvae of other groups with predacious habits (e.g. Adephaga, Hydrophiloidea, Cantharoidea; Beutel, 1993, 1995, 1999).
18. Prepharyngeal tube: (0) absent; (1) short, less than $50 \%$ of pharyngeal length between anatomical mouth and posterior attachment of $M .52$; (2) elongated, more than $50 \%$ of pharyngeal length

An open cibarium is found in larvae of Sphindus, Elateroides and Altica, and the non-predacious larvae of many groups of Coleoptera (e.g. Myxophaga part., Staphylinoidea part., Eucinetidae, Derodontidae; Beutel \& Molenda, 1997, Beutel et al., 1999). A short prepharyngeal tube (less than $50 \%$ of pharyngeal length) is present in larvae of Ericmodes, Zeonidicola, Mycetina, Silvanus, Oryzaephilus, Coccinella, Bitoma and Pyrochroa. An elongated prepharyngeal tube is present in the larvae of Phycosecidae, Cleridae and Trogossitidae. This presumably apomorphic condition is also characteristic of predacious larvae of other groups of Coleoptera such as Adephaga, Hydrophilidae, Histeridae, Elateroidea and Cantharoidea (Beutel, 1993, 1995, 1999).

19. Transverse hypopharyngeal muscle: (0) absent; (1) present

A transverse hypopharyngeal muscle is absent from larvae of Elateroides, Altica, Sphindus, Ericmodes, and other larvae of Cucujoidea (except for Silvanus) and Cleroidea. It is present in larvae of Pyrochroa and Bitoma, and larvae of other groups of Coleoptera (e.g. Catops, Necrophilus, Derodontus; Beutel \& Molenda, 1997; Beutel, 1995).

20. Strongly sclerotized transverse bar of hypopharynx: (0) absent; (1) present

A strongly sclerotized transverse bar connects the lateral walls of the hypopharynx in larvae of Collops, Phycosecis, Calytis, Temnoscheila, Lemidia, Zeonidicola, Sphindus and Ericmodes, and also in all other larvae of Cucujoidea and Tenebrionoidea examined, with the exception of Pyrochroa. The transverse bar is also absent from larvae of Altica and of other groups of Coleoptera (Beutel, 1993, 1995, 1996, 1999; Beutel \& Molenda, 1997).

21. Position of cerebrum: (0) within head capsule; (1) completely shifted to thorax; (2) partly shifted to prothorax and strongly asymmetric

The main part of the cerebrum lies within the head capsule in larvae of Elateroides, Altica, Sphindus (Figs. 7, 12, 13), Ericmodes and all other larvae of Cucujoidea and Tenebrionoidea. Only a part of the distinctly extended protocerebrum is shifted to the prothorax in early instar larvae of Ericmodes. The cerebrum and suboesophageal ganglion are completely shifted to the thorax in larvae of Cleroidea independent of their size (e.g. Calytis). A similar, presumably apomorphic condition is found in predacious larvae with prognathous head, distinctly extended attachment areas for $M$. craniomandibularis, and reduced postcerebral pharyngeal dilators (e.g. Hydrophilidae, Histeridae, Cantharoidea; Beutel, 1995, 1999). The cerebrum is partly shifted to the prothorax and markedly asymmetric in larvae of Nitidulidae and Melyridae.

22. Tube-like salivary glands: (0) absent; (1) present, unmodified 


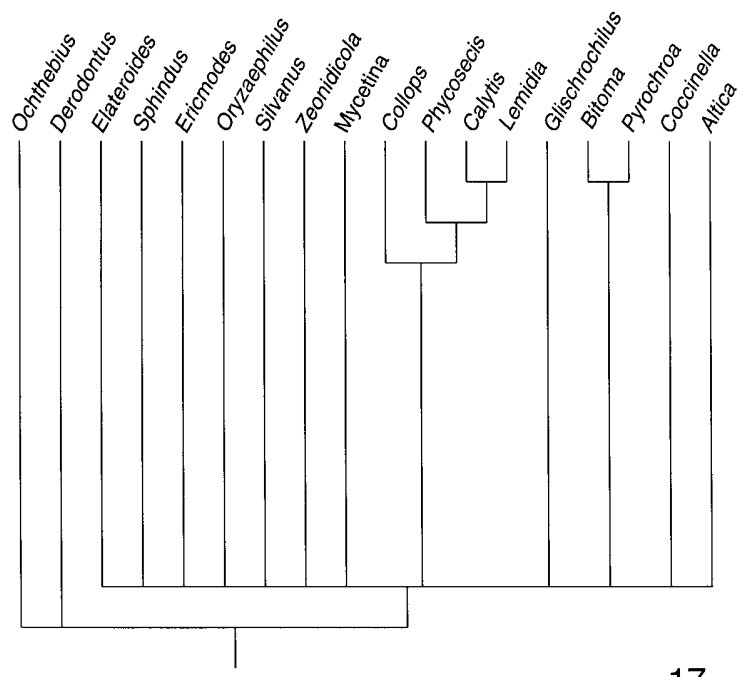

17

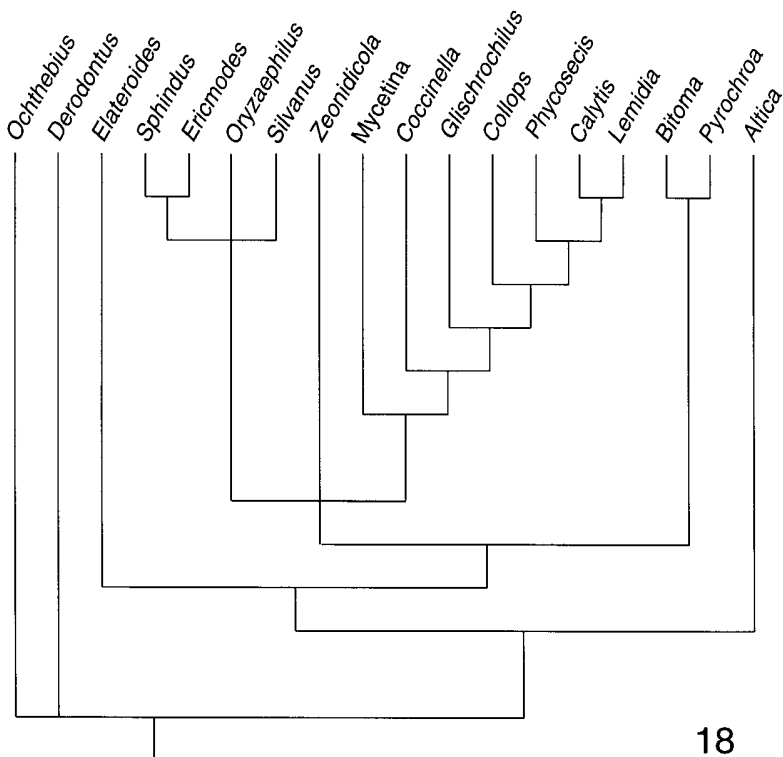

Figs 17-18: Cladograms. 17 - strict consensus tree of 74 trees with a minimal length of 63 steps; 18 - strict consensus tree of four trees obtained after successive reweighting.

Tube like salivary glands, resembling Malpighian tubules (Figs 7, 10,11), originate in the thorax or posterior head region in larvae of Cucujiformia. The proximal part is voluminous and grape-shaped in larvae of Altica. This is not coded as a separate character state. The tubes are absent from larvae of other groups such as Staphylinidae, Derodontidae, Nosodendridae and Dermestidae.

\section{ANALYSIS}

The preliminary analysis of the interrelationships of cucujiform taxa was based upon 22 larval characters. Ochthebius (Hydraenidae) and Derodontus (Derodontidae) were used as outgroups. All characters were weighted equally and not ordered. Question marks in the matrix indicate missing data.

Most parsimonious trees were sought using branch and bound search in PAUP (version 3.1; Swofford, 1991).
The outgroup taxa were treated as all other groups in the analysis (simultaneous analysis; Nixon and Carpenter, 1993). Analysis of character evolution was conducted in MacClade (version 3; Maddison and Maddison, 1992). Additional analyses were carried out after successive reweigthing. A bootstrap search was not conducted. Bootstrap values should not be used as confidence intervals (e.g. Carpenter, 1996; Rudolf Meier, pers. comm.).

The sample of taxa was restricted by the availability of larval material suitable for histological techniques. The genus Sphindus is apparently not a basal lineage within Sphindidae (McHugh ,1993; Chiao \& McHugh, in press). However, characters that are variable within this family (Chiao \& McHugh, in press) are not considered here.

\section{RESULTS OF THE PHYLOGENETIC ANALYSIS}

The analysis resulted in 74 trees of a minimal number of 63 steps (CI: 0.571; HI 0.429, RC 0.409). Interrelationships of cucujoid families were not resolved in a strict consensus tree (Fig. 17). Successive reweighting resulted in four equally parsimonious trees (Fig. 18: tree 1; Fig. 19 strict consensus tree). Unambiguous apomorphies are mapped on one of these trees and listed below for selected nodes.

The main purpose of the analysis was to determine the character state polarity and a preliminary assessment of some phylogenetic affinities. It is well understood that an analysis of features of the larval head of a very limited set of taxa cannot yield a reliable reconstruction of the interrelationships within Cucuiformia.

Cucujiformia: (2.1) diverging hypostomal rods (CI: $0.750)$; (4.1) dorsal tentorial arms flattened and weakly sclerotized (CI: 0.400); (5.1) anterior tentorial arms strongly reduced or absent, anterior tentorial grooves not connected with posterior tentorium (CI: 1.000); (9.1) prostheca absent (CI: 0.500); (14.2) maxillary mala (CI: 1.000); (22.1) tube-like glands present (CI: 1.000).

Cucujoidea, Cleroidea, Tenebrionoidea: (18.1) short prepharyngeal tube (CI: 0.667).

Cucujoidea, Cleroidea: (12.1) anterior component of M. tentoriostipitalis attached to ventral hypopharnygeal wall (CI: 1.000).

Sphindus and Ericmodes: (5.1) labrum almost vertical (CI: 0.500).

Mycetina, Coccinella, Glischrochilus, Collops, Phycosecis, Calytis, Lemidia: (3.1) posterior tentorial arms separated from bridge (CI: 1.000); (11.1) maxillolabial complex (CI: 1.000).

Coccinella, Collops, Glischrochilus, Phycosecis, Calytis, Lemidia: (1.2) gula short, sclerotized, inserted between posterior tentorial arms, fused with submentum (CI: 0.625).

Glischrochilus, Collops, Phycosecis, Calytis, Lemidia (Cleroidea): (2.0) hypostomal rods absent (CI: 0.750); (21.1) cerebrum asymmetrical (CI: 1.000).

Collops, Phycosecis, Calytis, Lemidia (Cleroidea): (1.4) gula moderately elongated, parallel-sided, unsclerotized (CI: 0.625); 7.1. antenna parallel to body axis (CI: 1.000); (16.0) M. tentoriopraementalis superior present (0.500); 


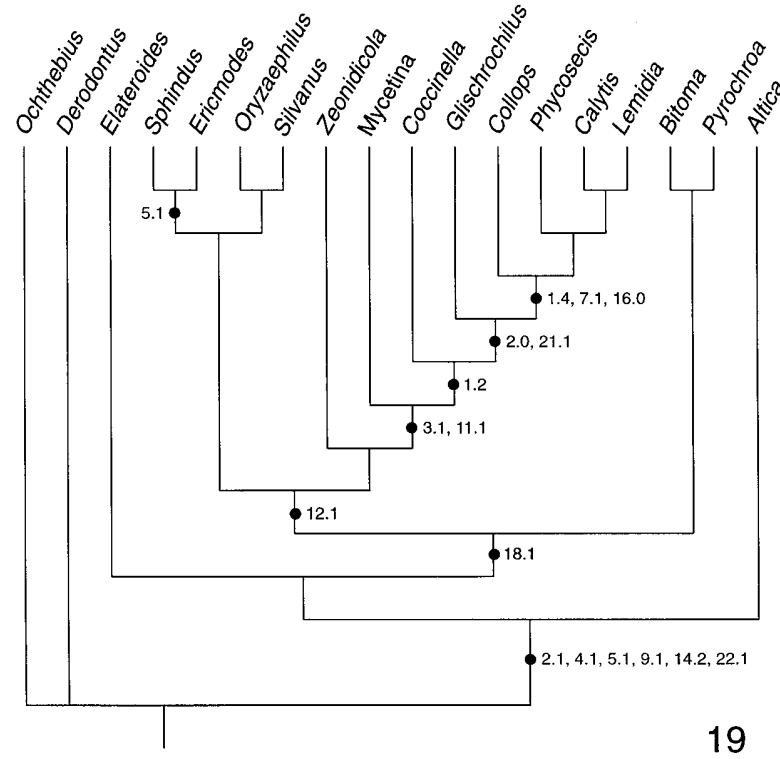

Fig. 19. Cladogram, tree 1 of four trees obtained after successive reweighting, unambiguous apomorphies mapped on cladogram for selected clades.

\section{DISCUSSION}

Larvae of Sphindus and Ericmodes show several presumably derived character states, which they probably share with all other larvae of Cucujiformia. Tube-like salivary glands, which were interpreted as a possible autapomorphy of this large lineage of Coleoptera, are unmodified in the larvae of Cleroidea, Cucujoidea, Tenebrionoidea, but distinctly extended and vesicular in larvae of Altica (Chrysomelidae). Other derived character states found in larvae of Ericmodes and Sphindus, and those of other cucujiform families, are the single mala and and a partly or completely reduced anterior tentorial arm, which is always disconnected from the posterior tentorium. The dorsal tentorial arm is weakly sclerotized or vestigial in most cucujiform larvae. However, this is more a tendency than a well defined character state. The tendency to shift the origin of the antennal muscles from the tentorium to the head capsule (all cleroid larvae, Elateroides, Altica, Bitoma, Pyrochroa) is probably correlated with this characteristic.

A monophyletic unit comprising cucujoid, cleroid and tenebrionoid taxa is only weakly supported by one unambiguous apomorphy, the presence of a short prepharyngeal tube. This implies secondary loss in Sphindus. Besides that, a prepharyngeal tube has evolved several times independently, associated with a predacious life style (e.g. Adephaga; Beutel, 1993).

The origin of an anterior component of M. tentoriostipitalis (M. 18) from the hypopharynx is an unusual derived character state, which indicates the monophyly of a large group comprising Cucujoidea and Cleroidea. This component is rather thin in Protocucujidae, Sphindidae, Silvanidae and Cavognathidae. A basal position of these groups within a presumptive cucujoid-cleroid lineage is also indicated by the comparatively plesiomorphic condition of the tentorium. The posterior arms and the tentorial bridge form a continuous structure, whereas they are separated from each other in larvae of the other groups. Another plesiomorphic feature is the absence of a maxillolabial complex. Restriction of the lateral movements of the maxillae is associated with increase in size of the vertically oriented hypopharyngeal component of M. 18 .

A sister group relationship between Protocucujidae and Sphindidae was suggested by Ślipiński (1998), based on the results of a cladistic analysis of larvae and adults of several groups of Cucujoidea (Sphindidae, Hobartiidae, Phoeostichidae, Brachypteridae). This seems to be well supported by shared derived adult features, especially of the male genital apparatus. However, proposed synapomorphic features of larvae are less convincing. The presence of only five stemmata (six in Sphindus) and a shortened coronal suture are character states found in many groups of Coleoptera. The larval head structures studied in this investigation do not yield much evidence for a sister group relationship between Protocucujidae and Sphindidae. A distinctly inclined or almost vertical labrum is characteristic of larvae of both families. However, this is a gradual modification rather than a distinct character state, and a similar condition is also found in larvae of other groups such as Staphylinidae (Sepedophilus) and Myxophaga (Beutel et al., 1999). Some character states seem to be more advanced in larvae of Ericmodes than in larvae of Sphindus. The head is almost prognathous, whereas it is distinctly inclined in larvae of Sphindus. They possess a closed prepharyngeal tube, which is absent from larvae of Sphindus, but present in larvae of other families of the cucujoid-cleroid lineage. The hypopharyngeal component of $\mathrm{M}$. tentoriostipitalis is slightly better developed and not separated from the posterior parts of the muscle. The mandibular prostheca is largely reduced in later instars. The brain is more elongated and partly shifted to the prothorax. These differences are not strong evidence against a sister group relationship between Protocucujidae and Sphindidae. Seemingly primitive characters of Sphindus, such as the absence of a gula, the distinctly inclined head, and the open cibarium, could be associated with their specialized slime mould feeding habits. It is apparent that more evidence is needed for a reliable interpretation of some character states and of the interrelationships between cucujiform groups.

ACKNOWLEDGEMENTS. We are greatly indebted to J.F. Lawrence (CSIRO Canberra), R. Leschen (New Zealand Arthropod Collection), and D.A. Pollock (Dept. of Entomology, University of Manitoba) for the gift of valuable specimens. Valuable comments and criticisms made by J. McHugh (University of Georgia) and an anonymous reviewer are gratefully acknowledged. We also wish to thank R.E. Roughley. Study of selected valuable specimens was made possible by Natural Sciences and Engineering Research Council of Canada, operating grant No. A0428 held by R.E.R. (Dept. of Entomology, University of Manitoba). The study was also supported by the Deutsche Forschungsgemeinschaft (R.G. Beutel, grant No. BE 1789/1-2). 


\section{REFERENCES}

Beutel R.G. 1993: Phylogenetic analysis of Adephaga (Coleoptera) based on characters of the larval head. Syst. Entomol. 18: 127-147.

BeUtel R.G. 1995: Phylogenetic analysis of Elateriformia (Coleoptera: Polyphaga) based on larval characters. J. Zool. Syst. Evol. Res. 33: 145-171.

BeUtel R.G. 1996: Study of the larva of Nosodendron fasciculare (Olivier 1790) (Coleoptera: Nosodendridae) with implications to the phylogeny of Bostrichiformia. J. Zool. Syst. Evol. Res. 34: 121-134.

BEUTEL R.G. 1999: Morphology and evolution of the larval head structures of Hydrophiloidea and Histeroidea (Coeloptera: Staphylinidae). Tijdschr. Entomol. 142: 9-30.

Beutel R.G. \& Molenda R. 1997: Comparative morphological study of larvae of Staphylinoidea (Coleoptera, Polyphaga) with phylogenetic implications. Zool. Anz. 236: 37-67.

Beutel R.G., Maddison D.R. \& HaAs A. 1999: Phylogenetic analysis of Myxophaga (Coleoptera) using larval characters. Syst. Entomol. 24: 171-192.

Böving A.G. \& CRAIGHEAD F.C. 1931: An illustrated synopsis of the principal larval forms of the order Coleoptera. Entomol. Am. 11: 1-125.

Burakowski B. 1997: Descriptions of larva and pupa of Mycetina cruciata (Schaller) (Coleoptera, Endomychidae). Ann. Zoologici 47 1-2: 209-215.

Burakowski B. \& ŚlupińsKi S.A. 1987: A new species of Protosphindus (Coleoptera: Sphindidae) from Chile with notes and descriptions of immature stages of related forms. Ann. Mus. Civ. St. Nat. Genova 86: 605-625.

CarPenter J.M. 1996: Uninformative bootstrapping. Cladistics 12: $177-181$

Chiao E. \& McHugh J.V.: Larval Sphindidae (Coleoptera: Cucujoidea): phylogenetic implications and new descriptions. Invertebr. Taxon. (in press).

Crowson R.A. 1954: The classification of the families of British Coleoptera. Entomol. Mon. Mag. 90: 57-63.

Crowson R.A. 1955: The Natural Classification of the Families of Coleoptera. Nathaniel Lloyd, London, $187 \mathrm{pp}$.

KÉLER S.V. 1963: Entomologisches Wörterbuch. Akademie Verlag, Berlin, $744 \mathrm{pp}$
Lawrence J.F. 1991: Phycosecidae (Cleroidea). Sphindidae (Cucujoidea) (including Aspidiphoridae). Cucujidae (Cucujoidea) (including Catogenidae, Laemophloeidae, Passandridae, Silvanidae). Mycetophagidae (Tenebrionoidea), Archaeocryptidae (Tenebrionoidea), Pterogeniidae (Tenebrionoidea), Ciidae (Tenebrionoidea) (= Cisidae, Cioidae), Tetratomidae (Tenebrionoidea), Melandryidae (Tenebrionoidea) (= Serropalpidae), Mordellidae (Tenebrionoidea), Colydidae (Tenebrionoidea) (including Adimeridae, Monoedidae), Monommidae (Tenebrionoidea), Zopheridae (Tenebrionoidea) (including Merycidae), Perimylopidae (Tenebrionoidea), Chalcodryidae (Tenebrionoidea), Cephaloidae (Tenebrionoidea) (including Nematoplidae, Stenotrachelidae), Oedemeridae (Tenebrionoidea), Mycteridae (Tenebrionoidea) (including Hemipeplidae), Trictenotomidae (Tenebrionoidea). In Stehr F.W. (ed.): Immature Insects, Vol. 2. Kendall/Hunt Publishing Company, Dubuque, Iowa, pp. 452, 463-466, 498-508, 512-515, 518-520, 529, 534-536, 539.

Lawson L. 1991: Chrysomelidae (Chrysomeloidea) (= Cassidiidae, Cryptocephalidae, Megalopidae, Sagridae, etc.). In Stehr F.W. (ed.): Immature Insects, Vol. 2. Kendall/Hunt Publishing Company, Dubuque, Iowa, pp. 568-585.

MAdDISON W.P. \& MADDISON D.R. 1992: MacClade, version 3: Analysis of phylogeny and character evolution. Sinauer, Sunderland, MA, 398 pp.

McHugh J.V. 1993: A revision of Eurysphindus LeConte (Coleoptera: Cucujoidea: Sphindidae) and a review of sphindid classification and phylogeny. Syst. Entomol. 18: 57-92.

McHugh J.V. \& LewIS C.N. 2000: Three new species of Carinisphindus McHugh (Coleoptera: Sphindidae) from Bahamas, Florida and Puerto Rico. Coleopt. Bull. (in press).

Nixon K.C. \& CARPENTER J.M. 1993: On outgroups. Cladistics 9: $413-426$.

ŚLIPIŃsKI S.A. 1998: Revision and phylogeny of Protocucujidae (Coleoptera: Cucujoidea). Ann. Zoologici 48: 275-298.

SwOFFord D.L. 1991: PAUP: Phylogenetic analysis using parsimony, version 3.1. Computer program distributed by the Illinois Natural History Survey, Champaign, Illinois.

Received March 6, 2000; accepted June 22, 2000 